International Journal of Maternal and Child Health and AIDS (202I), Volume I0, Issue I, I09-I I 2

\begin{tabular}{ll}
\hline & INTERNATIONAL JOURNAL of \\
& MATERNAL and CHILD HEALTH and AIDS \\
& ISSN 216I-864X (Online) \\
& ISSN 216I-8674 (Print) \\
\hline IJMA Available online at www.mchandaids.org & DOI: $10.21106 /$ ijma.4I9 \\
\hline
\end{tabular}

SHORT RESEARCH COMMUNICATION | COVID-I 9

\title{
A Framework for Protecting Pregnant Women in the Era of COVID-19 Pandemic
}

\author{
Deepa Dongarwar, MS; ${ }^{\bowtie}$ Veronica B.Ajewole, PharmD;2,3,4 Kiydra Harris, PharmD; ;,3,5 \\ Emmanuella Oduguwa, BS;' Theresa U. Ofili, RN, PharmD, MPH; ${ }^{6}$ Collins Onyenaka, BPharm; ${ }^{3}$ \\ Sade Arnold; Jorhn Broussard; Joan Ishioye; ${ }^{3}$ Jasmine Marshal, MHA; ${ }^{3}$ Jamila Mayoya; ${ }^{3}$ Danchau Le, BS; ${ }^{3}$ \\ Mouch Fadel ${ }^{3}$, Omonike A. Olaleye, $\mathrm{PhD}, \mathrm{MPH} ;{ }^{2,3}$ Hamisu M. Salihu MD, PhD ${ }^{1,3,7}$ \\ 'Center of Excellence in Health Equity, Training, and Research, Baylor College of Medicine, Houston, TX, USA, ${ }^{2}$ College of Pharmacy and Health Sciences, \\ Texas Southern University, Houston, TX, USA, ${ }^{3}$ Maternal and Child Health Student Training Program, Texas Southern University, Houston, TX, USA, \\ ${ }^{4}$ Houston Methodist Hospital, Houston, TX, USA, ${ }^{5}$ Harris Health System, Houston, TX, USA, ${ }^{6}$ Irma Lerma Rangel College of Pharmacy, Texas A\&M \\ University, College Station, TX, 'Department of Family and Community Medicine, Baylor College of Medicine, Houston, TX, USA \\ $\triangle$ Corresponding author email: deepa.dongarwar@bcm.edu
}

\section{ABSTRACT}

The severe acute respiratory syndrome coronavirus 2 (SARS-CoV-2), the causative agent for the coronavirus disease 2019 (COVID-19) pandemic, highlighted and compounded problems while posing new challenges for the pregnant population. Although individual organizations have provided disparate information, guidance, and updates on managing the pregnant population during the current COVID-I 9 pandemic, it is important to develop a collective model that highlights all the best practices needed to protect the pregnant population during the pandemic. To establish a standard for ensuring safety during the pandemic, we present a framework that describes best practices for the management of the pregnant population during the ongoing COVID-I9 pandemic.

Key words: • COVID-19 • Pregnant women $\bullet$ maternal and child health $\bullet$ program design and implementation $\bullet$ framework $\bullet$ professional associations $\bullet$ special considerations

Copyright $\odot 202$ I Dongarwar, et al. Published by Global Health and Education Projects, Inc. This is an open-access article distributed under the terms of the Creative Commons Attribution License CC BY 4.0.

\section{Introduction}

The coronavirus disease 2019 (COVID-19) pandemic, caused by severe acute respiratory syndrome coronavirus 2 (SARS-CoV-2), was first identified in Wuhan, China in December 2019.' The COVID- 19 pandemic has significantly impacted social, occupational, and healthcare practices globally. ${ }^{2}$ For the pregnant women's population, who naturally face special risks related to childbearing and overall development, the COVID-I 9 pandemic has imposed more challenges and put this population at greater risk.

During pregnancy and child development, immunologic changes occur that may induce a state of increased susceptibility to certain intracellular pathogens, including viruses, intracellular bacteria, and parasites. $^{3}$ The World Health Organization (WHO) reports that the current basic reproduction number $\left(R_{0}\right)$ of SARS-CoV-2 is within the estimated range of I.4-2.5; this value exceeds the previous $R_{0}$ 
of the 2012 SARS-CoV-I pandemic. The $R_{0}$ value implies that human host infected with SARS-CoV-2 can spread the virus to about $1.4-2.5$ extra hosts. ${ }^{4}$ Thus, we can assume extra precautions should be taken by pregnant women, children, and their families to prevent community spread of COVID-I9.

Various organizations such as the American College of Obstetricians and Gynecologists (ACOG), and the Maternal and Child Health Bureau at the Health Resources and Services Administration (HRSA) of the U.S. Department of Health and Human Services have developed separate advisory guidance/ updates by constructing resources that will be useful in providing safe and high-quality care to mothers and babies during the COVID- 19 pandemic. ${ }^{5,6}$ In addition, with the pandemic in place, some states have been able to redirect funds from Title $\mathrm{V}$ grants (the U.S. federal grant programs of support for promoting and improving the health and well-being of the nation's mothers, children, and family) to assist in investigations, education/ information provision, emergency preparedness and infrastructure. ${ }^{7}$ Although standalone information and guidance on managing the pregnant population during the current COVID-19 pandemic are being created, it is important to develop a cohesive model that highlights all the best practices. In this study, we propose a framework for the health management of pregnant women during the ongoing COVID- 19 pandemic.

\section{Methods}

This study was conducted by the participants of the Maternal and Child Health $(\mathrm{MCH})$ Student Training Program at Texas Southern University and the Center of Excellence in Health Equity Training program at Baylor College of Medicine. Using Nominal Group Technique (NMT), we developed a unidirectional conceptual framework based on program-articulated tasks that could positively influence short- and long-term outcomes of program design and implementation for pregnant population during the COVID-I9 pandemic. The senior author was the moderator of the NMT and conducted the survey to devise the components that should be considered in the program design. Then all participants prioritized and ranked the components; and the final components were included in the final framework.

When designing the program framework to best manage the pregnant patients during the COVID- 19 pandemic, a variety of areas of focus were considered and finalized, including provider/patient planning and coordination, personnel, preventative measures, COVID-19 testing, community and physical distancing, telehealth, personal protective equipment, supplies, prioritization of care, ongoing assessment, patient communication, and disparities. We believe that activities and procedures targeting a pregnant woman in the era of COVID-19 pandemic will be best implemented across important milestones of the three main pregnancy and childbirth related periods. These are (I) the early prenatal period, (2) late prenatal period, and (3) the peripartum period. Our framework is analogous to the life course theory, a conceptual framework that has been extensively utilized to explain cumulative burden of disease and differential outcomes across different population groups over time. ${ }^{7}$

\section{Results}

Figure I illustrates details of our framework for protecting pregnant women during the COVID-19 pandemic, which is divided into 5 sections. In this framework, we postulate that the perinatal period could be divided or classified into the early prenatal period, late prenatal period, and peripartum period, and the best practices to be followed for protection of pregnant women and their children include healthcare visits, supplements, safe breastfeeding practices, etc. During these periods, telecommunication and telemedicine are being used for prenatal/postnatal care and discharge/follow up visits for low risk patients. ${ }^{8}$ During the peripartum period, other grave concerns encompassing the spread of COVID-19 is the possibility of the mother passing the virus to the unborn child. According to the Centers for Disease Control and Prevention (CDC), there is no evidence at this time to support or contradict the claim that COVID-19 can be passed to an unborn child in utero. ${ }^{9}$ Therefore, recommended vaccinations such as the influenza and Tdap should be continued, to protect both the 


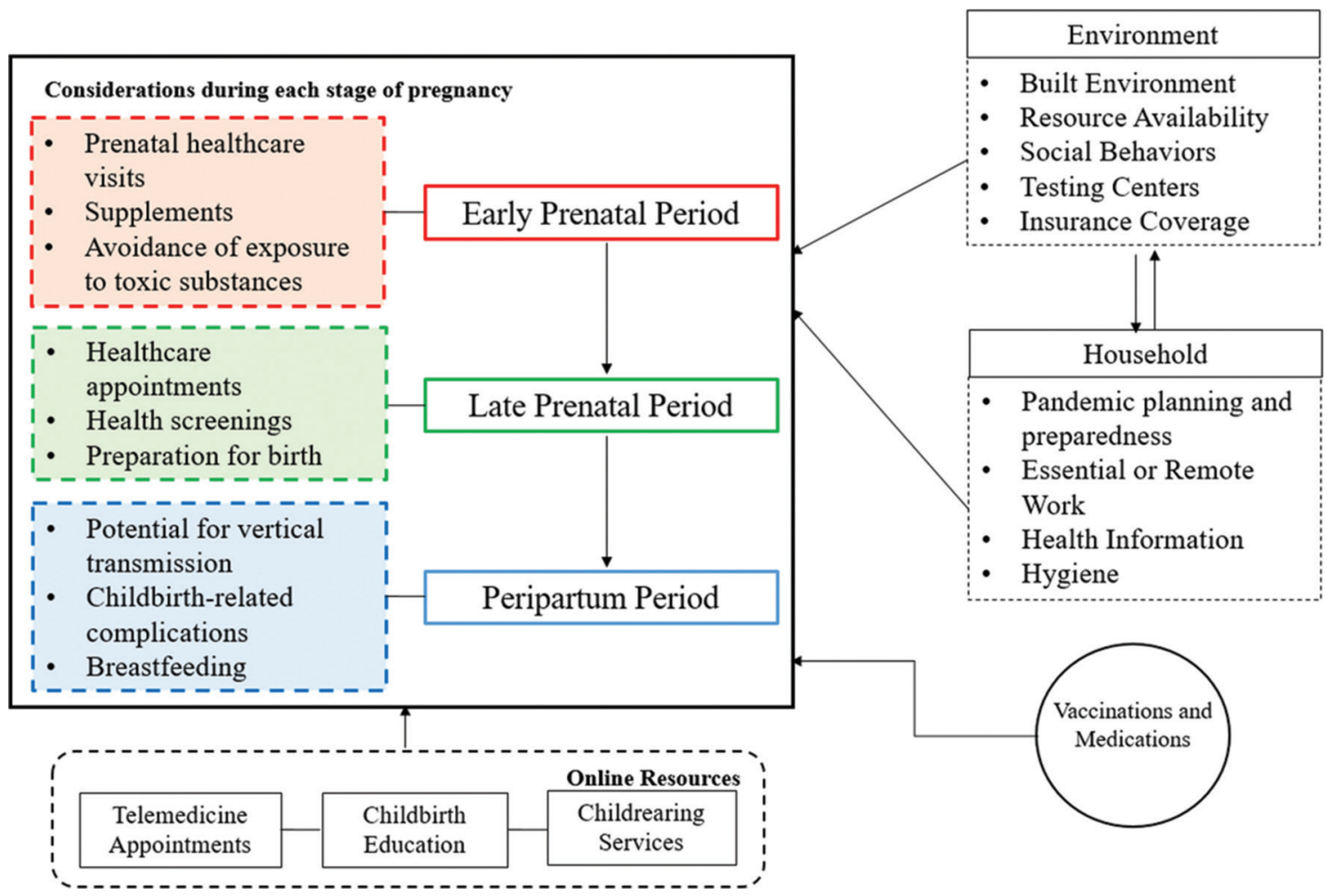

Figure I. Framework for Protecting Pregnant Women During the COVID-19 Pandemic

mother and infant. ${ }^{9}$ The environmental factors such as social behaviors of proper distancing, face covering, etc. and availability of resources, such as access to testing centers, medical assistance and insurance coverage; and household factors such as pandemic planning and preparedness, hygiene practices etc. are extremely important in maintaining good health for the pregnant women. Together with considerations at each stage of the pregnancy, environmental and household safety protocols, updated vaccination and medication records; and online resources provided by various organizations, pregnant population could be safeguarded and protected during this COVID-19 pandemic.

\section{Discussion And Global Health Implications}

Ensuring the health of mothers, infants, and children is important because it mirrors the health of the next generation. Naturally, many factors can affect pregnancy and childbirth, and the addition of a novel and rapidly evolving virus like COVID- 19 drastically shifts how the Maternal and Child Health $(\mathrm{MCH})$ population should be managed-requiring more safety precautions, special considerations, and new program implementation. The social determinants of health $(\mathrm{SDOH})$ are known to contribute to worse outcomes in the maternal population. ${ }^{10}$ Therefore, surveillance system to protect the $\mathrm{MCH}$ population is extremely important during the current COVID- 19 pandemic."

The COVID-19 pandemic underscores the necessity for special considerations for pregnant women and family engagement.Special considerations for the pregnant population should include review of insurance availability. About $49 \%$ of Americans have employer provided health insurance. ${ }^{12}$ Loss of health insurance due to unemployment has increased during the pandemic as a result of stay-at-home orders and business closures. The potential impact 
of increased uninsured $\mathrm{MCH}$ patients infected with COVID- 19 poses another public health emergency.

For the pregnant population, the COVID-19 pandemic has highlighted and complicated already occurring problems while posing new public health emergencies. To continue working towards improved $\mathrm{MCH}$ equity, special considerations, direct support, adequate resources, and best practice program implementation should be driven by policy makers, healthcare systems, and $\mathrm{MCH}$ focused non-profit organizations. This framework has been developed by the research team and remains untested at this point. Future researchers and policy makers should utilize this framework to validate and implement programs for protection of pregnant women's population during the pandemic.

\section{Compliance with Ethical Standards}

Conflicts of Interest: None from all authors and co-authors. Financial Disclosure: None. Funding/Support: This work was funded by the Health Resources and Services Administration's Maternal and Child Health Student Training Program (HRSA-MCH; TI6MC2983I) and U.S. Department of Health and Human Services and Health Resources and Services Administration for Baylor College of Medicine Center of Excellence in Health Equity, Training, and Research (Grant No: D34HP3 1024). Ethics Approval: Not applicable. Acknowledgements: Not applicable. Disclaimer: None.

\section{Key Messages}

Distinctive considerations during each stage of the pregnancy: early prenatal, late prenatal and peripartum periods, are required to maintain health and prevent complications in pregnant women during the COVID-19 pandemic Recommended vaccinations such as influenza and Tdap should be continued, during the pregnancy, despite the pandemic to protect both the mother and the infant

Environmental and household preparedness, with assistance from online resources will help women protecting themselves and their infants during the COVID-19 pandemic

\section{References}

I. Centers for Disease Control and Prevention. Coronavirus (COVID-19) frequently asked questions. https://www. cdc.gov/coronavirus/2019-ncov/faq.html\#In-Case-of-anOutbreak-in-Your-Community. Published June 17, 2020. Accessed June 12, 2020.

2. Johns Hopkins University. Johns Hopkins Coronavirus Resource Center. https://coronavirus.jhu.edu/. Published 2021 . Accessed February 5, 2021.

3. Jamieson DJ,Theiler RN, Rasmussen SA. Emerging infections and pregnancy. Emerg Infect Dis. 2006; I2(II):I638-1643. doi:10.3201/eidI2II.060152

4. Mahase E. China coronavirus: what do we know so far? BMJ. 2020;368:m308 doi:I0.II36/bmj.m308. Published January 24, 2020. Accessed June I2, 2020.

5. The American College of Obstetricians and Gynecologists. COVID-19. https://www.acog.org/en/COVID-19. Published 2021.Accessed February 5, 2021

6. Health Resources and Services Administration. Coronavirus (COVID-19) Information. https://www.hrsa.gov/ coronavirus. Published 2021. Accessed February 5, 2021.

7. Lu M, Halfon N. Racial and Ethnic Disparities in Birth Outcomes: A Life-Course Perspective. Matern Child Health J. 2003;7(I): I3-30. doi: I0.1023/a: I0225375 I6969

8. American Hospital Association. Maternal and Child Health During COVID-19.; 2020. https://www.aha.org/system/files/ media/file/2020/05/COVID-19-Maternal-Guidelines_rev6. pdf.Accessed June I2, 2020.

9. Centers for Disease Control and Prevention. If You Are Pregnant, Breastfeeding, or Caring for Young Children. https://www.cdc.gov/coronavirus/2019-ncov/need-extraprecautions/pregnancy-breastfeeding.html. Published June 9, 2020. Accessed June 12, 2020.

10. Dongarwar D,Ajewole VB, Oduguwa E, et al. Role of Social Determinants of Health in Widening Maternal and Child Health Disparities in the Era of Covid-19 Pandemic. Int J MCH AIDS. 2020;9(3):3 I6-319. doi: I0.2 I I06/ijma.398

II. Ajewole VB, Ngujede AE, Oduguwa E, et al. A Surveillance System for the Maternal and Child Health $(\mathrm{MCH})$ Population During the COVID-19 Pandemic. Int J MCH AIDS. 2020;9(3):350-353. doi: I0.2 I 106/ijma.4I I.

12. Kaiser Family Foundation. Health Insurance Coverage of the Total Population Data (2008-2018). https://www.kff.org/ other/state-indicator/total-population/.Accessed July I, 2020. 